\title{
Varieties and Pre Harvesting Treatment for Growing Polish Canola (Brassica rapa L.) in Interior Alaska
}

\author{
Mingchu Zhang", R. Van Veldhuizen \\ Department of Agriculture and Horticulture, School of Natural Resources and Extension, University of Alaska Fairbanks, USA
}

Copyright $(2016$ by authors, all rights reserved. Authors agree that this article remains permanently open access under the terms of the Creative Commons Attribution License 4.0 International License

\begin{abstract}
Barley has been a mono cereal crop grown in the Delta Junction area of Alaska since 1970s. A rotational crop is needed for weed control and conservation tillage for sustainable crop production. Due to short growing season constrains, canola when used as a rotational crop currently resulted low marketability because of high green seed content $(>2 \%)$. The objective of this research is to determine if glyphosate when used as a desiccating chemical could promote early maturity and reduce green seed content of canola. Four Polish canola cultivars were treated with direct combine (as a control), pushing (to stop growth) and desiccating in two locations in Alaska USA in a randomized complete block design with four replicates from 2007 to 2009. Glyphosate was sprayed, and pushing was conducted around August 15 each year. Results showed that 'Hysin 110' treated by glyphosate consistently had $\leq 2 \%$ green seed content in three years in contrast with 'Reward' despite a wide variation of weather conditions. The growing degree days were dramatically different among the three years, with 2009 close to the 29-year norm, 2008 was lower and 2007 was higher than the norm. No residual glyphosate was found in the seeds from the desiccating treatment. In conclusion, desiccating treatment together with a good short growing season Polish canola cultivar can make canola grown as a rotational crop in Alaska's short growing season conditions.
\end{abstract}

Keywords Brassica rapa, Polish Canola, Pre-harvest Treatments, Glyphosate, Alaska, Oil Quality

\section{Introduction}

Table 1. Canola test results prior to 2007 in the Delta Junction area of Alaska.

\begin{tabular}{|c|c|c|c|c|c|c|}
\hline Variety & Sources (breeder) & Started year & No. of years tested & Average yield & Average date to maturity & Green seed (\%) \\
\hline & & & & & & \\
\hline Colt & Sweden & 1994 & 7 & 1264 & Aug. 18 & 9 \\
\hline Eldorado & Alberta, Canada & 1993 & 5 & 730 & Aug. 18 & 2 \\
\hline Goldrush & Sweden & 1996 & 2 & 1319 & Aug. 27 & 3 \\
\hline Horizon & Sweden & 1994 & 7 & 1419 & Aug. 17 & 6 \\
\hline Hysin110 & Manitoba, Canada & 2006 & 1 & 1348 & Aug. 15 & 2 \\
\hline Maverick & Sweden & 1996 & 4 & 1574 & Aug. 10 & 4 \\
\hline Reward & Manitoba, Canada & 1993 & 11 & 1245 & Aug. 16 & 8 \\
\hline Sunshine & Alberta, Canada & 1994 & 7 & 1818 & Aug. 18 & 7 \\
\hline
\end{tabular}

Barley (Hordeum vulgare $\mathrm{L}$ ) has been grown in the Delta Junction area $\left(64^{\circ} 49^{\prime} \mathrm{N}, 147^{\circ} 52^{\prime} \mathrm{W}\right)$ of Alaska since land conversion to agriculture in the 1970s. The soils in the area are predominantly silt loams formed from glacial rock flour and re-deposited by wind and water. Clay content in soils usually is less than $10 \%$ and soil structure is poorly developed due to the short growing season, and it is vulnerable for erosion. Continuous barley mono crop system will cause soil quality deterioration and lack of rotational crop and weed control have prevented adoption of no tillage practice in the area. No tillage practice in the region shows that it reduces soil erosion by wind or water, and improves soil quality (Sharrat et al. 2006a, 2006b, Zhang et al. 2007). However, lack of no rotational crop often makes weed control difficult in no tillage field. Five chemical fallows were used in a 23 year no tillage experiment in the Delta Junction area of Alaska (Zhang, unpublished results). Therefore, a broad leaf rotational crop like canola is needed in the area in order to adopt no tillage practice to conserve soil from erosion and sustain small grain production in the region.

Several polish canola (Brassica rapa $\mathrm{L}$.) varieties have been tested as rotational crops in the past but were not successful due to late maturity and high green seed content (Table 1). With introduction of new canola varieties and development of harvesting technologies, canola might serve as a potential rotational crop in the Alaska. The objective of this presentation is to determine a suitable canola variety and harvesting technologies to make the canola as a viable crop in interior Alaska. 


\section{Materials and Methods}

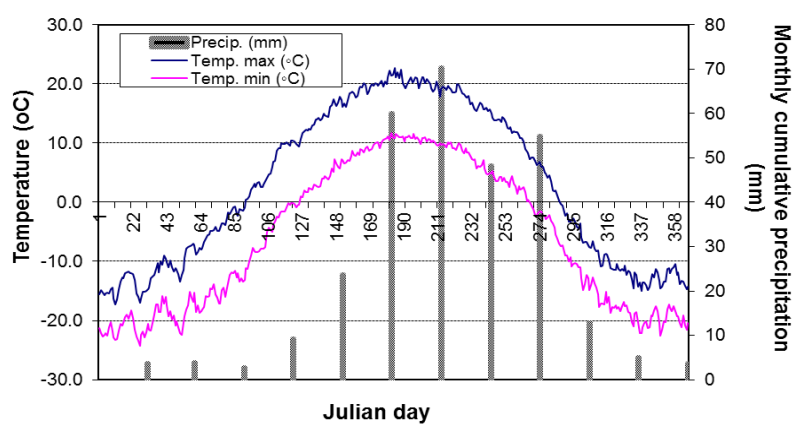

Figure 1. Yearly average (1980-2009) of air temperature and precipitation in the Delta Junction area of Alaska.

The experiment was conducted in the research farms of Agriculture and Forestry Experimental Station of the University of Alaska Fairbanks in Delta Junction area and in Fairbanks from 2007 to 2009. The area has an annual precipitation of $300 \mathrm{~mm}$ and mean temperature of $-3^{\circ} \mathrm{C}$. The 29-year mean precipitation and temperature from May to September were summarized in Figure 1. Soil in the Delta Junction area is Volkmar silt loam (Aquic Cryochept, US Taxonomy, USDA NRCS) and in the Fairbanks area is Tanana silt loam (Typic Aquiturbel, USDA NRCS). Four Polish type canola varieties were used in the experiment, 'Reward', 'Hysin 110', 'Maverick', and 'Sunbeam' with a same seeding rate of $13 \mathrm{~kg}$ seeds $/ \mathrm{ha}$. Sunbeam was a new Polish canola variety developed in Manitoba Canada, which we collected seeds in 2008 and tested it in the field experiment in 2009. We had a limited seeds for Sweden cultivar 'Marerick', therefore, it was only tested in 2007. There were three harvesting treatments: direct combining (as a control), desiccating, and pushing (to stop growth). The experiments were arranged in a randomized complete block design with four replicates. For direct combine treatment, plots were harvested with a plot combine in late August or early September when canola was ripe, depending on weather conditions. The desiccate treatment was implemented by spraying glyphosate $(1.5 \%)$ on Aug. 13, 2007 and Aug. 12, 2008 for both Delta Junction and Fairbanks, and Aug. 10 and Aug. 11, 2009 for Delta Junction and Fairbanks, respectively. The plots were then harvested using a plot combine at the same time as the direct combine treatment. For pushing treatment, canola was pushed around Aug. 15 for all three years by a steel tool bar mounted on the three point hitch of a tractor. The tool bar was set to a height of about $13 \mathrm{~cm}$ above ground. The tractor was then backed over the plots to push or crimp the stem for stopping growth. Those plots were also harvested using a plot combine at the same time as the direct combine treatment in late August or early September. The seeds harvested from each plot were dried in an oven at $60^{\circ} \mathrm{C}$ and weighed. The content of green seeds in each treatment was determined by placing 100 seeds in a plastic panel which has $100,0.32 \mathrm{~cm}$ depression drilled into surface to catch one canola seed in each depression. A strip of clear strapping tape was then placed on a sheet of white paper and crushed with a hard plastic roller and the number of green seeds were counted afterward. To test viable seeds from different pre-harvesting treatments, four replicated 100 seeds were placed in moist paper tower, and placed in an aluminum foil pan with a cover. The germinated seeds were counted in 15 days.

Twenty nine year weather data at the Delta Junction area (1980 - 2009) were obtained from National Climate Data Center (https://www.ncdc.noaa.gov/), and were averaged for precipitation and minimum and maximum temperature during the growing season (Fig. 1). We only obtained the weather data in the Delta Junction area due to the proximity of the two sites, and Delta Junction area is the major small grain production area in Alaska. Growing degree day was calculated using $0^{\circ} \mathrm{C}$ as a base.

All data were statistically analyzed with ANOVA for a split-plot design (variety as main, and pre-harvesting treatment as sub plot) and mean comparison among treatments variety and pre-harvesting treatments. The software for the statistical analysis was Statistix 11 by Analytical Software (Tallahassee, FL, USA).

\section{Results and Discussion}

Geographically, Delta Junction and Fairbanks areas are located in subarctic regions with annual temperature below zero Celsius. Discontinuous permafrost exists in the both areas. Planting time usually occurs in early May, and harvesting in late August (Fig. 1). The small grain crop that is predominantly grown in the area is barley. Locally developed short growing season hard red spring wheat (Triticum aestivum cv. 'Ingal') can reach maturity in the area. But due to seed shattering issue at maturity for this cultivar, it has not been widely grown in the area. Both areas have large acreages suitable for agriculture, which can be a potential area for small grain production in USA (NASS, 2012). Currently, Delta Junction is the major small grain production area in Alaska. The success of a rotational crop in the area is significant for sustainable agricultural production.

Our results showed that direct combining resulted in apparent higher yield as compared to the other two harvesting technologies in Delta Junction area (Table 2). The pushing treatment had the lowest yield in all three years and varieties due to shattering of Polish canola seed pods caused by pushing. In contrast, at the Fairbanks site, the desiccate treatment yielded higher for all three cultivars in 2007 (Table 3). Seed for cultivar 'Maverick' was available in 2007 but not available in 2008 and 2009. Seed of 'AC Sunbeam', a newly released Polish canola variety from western Canada, was available in 2009. As shown in Tables 2 and 3, 'Hysin

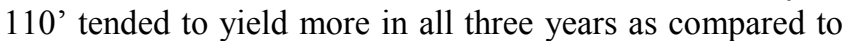
'Reward'. But the variety was phased out after it was purchased by a private seed company. Desiccation treatment consistently showed that in three years it decreased green seeds content of harvested seeds (Table 2, Table 3). 'Maverick', which has been tested in the both sites for four years prior to this experiment (Table 1), showed a decrease in green seed content after use of desiccation treatment. 
Similar observation was found for 'Reward', which had been tested for 11 years before this experiment (Table 1). In all tested cultivars, 'Hysin 110' consistently had a lower green seed content $(<2 \%)$ for both sites. But for other cultivars, green seed content in desiccate treatment in 2008 had more than $2 \%$ green seed content (Table 2, Table 3 ).

Table 2. Yield results of harvesting treatments for all tested canola cultivars from 2007 to 2009 at Delta Junction site.

\begin{tabular}{|c|c|c|c|c|c|c|c|}
\hline \multirow[t]{2}{*}{ Variety } & \multirow[t]{2}{*}{ Harvesting tech. } & \multicolumn{3}{|c|}{ Yield (kg/ha) } & \multicolumn{3}{|c|}{ Green seed content $(\%)$} \\
\hline & & 2007 & 2008 & 2009 & 2007 & 2008 & 2009 \\
\hline \multicolumn{8}{|l|}{ Delta Junction } \\
\hline \multirow[t]{3}{*}{ Reward } & Direct combining & $1748 \pm 408$ & $1515 \pm 134$ & $928 \pm 136$ & 4 & 19 & 4 \\
\hline & Desiccate & $1993 \pm 286$ & $1468 \pm 160$ & $826 \pm 96$ & 1 & 7 & 1 \\
\hline & Pushing & $1015 \pm 70$ & $1396 \pm 187$ & $521 \pm 126$ & 2 & 10 & 2 \\
\hline \multirow[t]{3}{*}{ Hysin 110} & Direct combining & $2055 \pm 291$ & $1981 \pm 89$ & $937 \pm 135$ & 3 & 8 & 5 \\
\hline & Desiccate & $1972 \pm 439$ & $1721 \pm 63$ & $818 \pm 194$ & 1 & 1 & 1 \\
\hline & Pushing & $1256 \pm 323$ & $1584 \pm 66$ & $515 \pm 153$ & 3 & 3 & 2 \\
\hline \multirow[t]{3}{*}{ Maverick } & Direct combining & $1012 \pm 217$ & NA & NA & 4 & NA & NA \\
\hline & Desiccate & $1705 \pm 331$ & NA & NA & 1 & NA & NA \\
\hline & Pushing & $862 \pm 258$ & NA & NA & 3 & NA & NA \\
\hline \multirow[t]{3}{*}{ Sunbeam } & Direct combining & NA & NA & $934 \pm 259$ & NA & NA & 3 \\
\hline & Desiccate & NA & NA & $887 \pm 159$ & NA & NA & 2 \\
\hline & Pushing & NA & NA & $471 \pm 90$ & NA & NA & 2 \\
\hline \multicolumn{8}{|c|}{ Average for variety } \\
\hline Reward & & $1598 \mathrm{~b}$ & $1460 \mathrm{~b}$ & 771 & 2 & 2 & $3 \mathrm{a}$ \\
\hline Hysin 110 & & $1761 \mathrm{a}$ & $1763 \mathrm{a}$ & 757 & 2 & 2 & $3 \mathrm{a}$ \\
\hline Marverick & & $1204 \mathrm{c}$ & NA & NA & 3 & NA & NA \\
\hline Sunbeam & & NA & NA & 765 & NA & NA & $2 \mathrm{~b}$ \\
\hline Probability (F test) & & 0.01 & 0.01 & 0.88 & 0.11 & 0.71 & 0.02 \\
\hline \multicolumn{8}{|c|}{ Average for harvesting methods } \\
\hline Direct combining & & $1617 \mathrm{~b}$ & $1748 \mathrm{a}$ & $933 \mathrm{a}$ & $3 \mathrm{a}$ & $3 \mathrm{a}$ & $4 \mathrm{a}$ \\
\hline Desiccate & & $1890 \mathrm{a}$ & $1559 \mathrm{~b}$ & $856 \mathrm{a}$ & $1 \mathrm{~b}$ & $1 \mathrm{~b}$ & $1 \mathrm{c}$ \\
\hline Pushing & & $1056 \mathrm{c}$ & $1527 \mathrm{~b}$ & $503 \mathrm{~b}$ & $3 a$ & $3 a$ & $2 \mathrm{~b}$ \\
\hline Probability (F test) & & $<0.01$ & $<0.01$ & $<0.01$ & $<0.01$ & $<0.01$ & $<0.01$ \\
\hline
\end{tabular}

Table 3. Yield results of harvesting treatments for all tested canola cultivars from 2007 to 2009 at Fairbanks site.

\begin{tabular}{|c|c|c|c|c|c|c|c|}
\hline \multirow[t]{2}{*}{ Variety } & \multirow[t]{2}{*}{ Harvesting tech. } & \multicolumn{3}{|c|}{ Yield (kg/ha) } & \multicolumn{3}{|c|}{ Green seed content $(\%)$} \\
\hline & & 2007 & 2008 & 2009 & 2007 & 2008 & 2009 \\
\hline \multicolumn{8}{|l|}{ Delta Junction } \\
\hline \multirow[t]{3}{*}{ Reward } & Direct combining & $1225 \pm 415$ & $1391 \pm 169$ & $1075 \pm 317$ & 4 & 7 & 5 \\
\hline & Desiccate & $1755 \pm 420$ & $2169 \pm 108$ & $2206 \pm 230$ & 1 & 4 & 1 \\
\hline & Pushing & $1073 \pm 248$ & $1075 \pm 486$ & $1026 \pm 277$ & 5 & 4 & 4 \\
\hline \multirow[t]{3}{*}{ Hysin 110} & Direct combining & $1149 \pm 551$ & $1909 \pm 430$ & $813 \pm 488$ & 4 & 7 & 3 \\
\hline & Desiccate & $1880 \pm 207$ & $2656 \pm 78$ & $2425 \pm 103$ & 2 & 2 & 1 \\
\hline & Pushing & $1014 \pm 630$ & $1378 \pm 398$ & $1484 \pm 508$ & 2 & 6 & 3 \\
\hline \multirow[t]{3}{*}{ Maverick } & Direct combining & $1390 \pm 574$ & NA & NA & 5 & NA & NA \\
\hline & Desiccate & $2330 \pm 289$ & NA & NA & 1 & NA & NA \\
\hline & Pushing & $1209 \pm 461$ & NA & NA & 5 & NA & NA \\
\hline \multirow[t]{3}{*}{ Sunbeam } & Direct combining & NA & NA & $1166 \pm 439$ & NA & NA & 2 \\
\hline & Desiccate & NA & NA & $2291 \pm 147$ & NA & NA & 1 \\
\hline & Pushing & NA & NA & $1413 \pm 292$ & NA & NA & 3 \\
\hline \multicolumn{8}{|c|}{ Average for variety } \\
\hline Reward & & $1351 \mathrm{~b}$ & $1544 \mathrm{~b}$ & 1496 & $3 \mathrm{~b}$ & 5 & $3 \mathrm{a}$ \\
\hline Hysin 110 & & $1347 \mathrm{~b}$ & $1981 \mathrm{a}$ & 1574 & $4 \mathrm{a}$ & 5 & $2 \mathrm{~b}$ \\
\hline Marverick & & $1643 \mathrm{a}$ & & 1623 & $3 \mathrm{~b}$ & & \\
\hline Sunbeam & & & & & & & $2 \mathrm{~b}$ \\
\hline Probability ( $\mathrm{F}$ test) & & 0.02 & $<0.01$ & 0.69 & 0.02 & 0.63 & $<0.01$ \\
\hline & & & & & & & \\
\hline \multicolumn{8}{|c|}{ Average for harvesting methods } \\
\hline Direct combining & & $1255 \mathrm{~b}$ & $1650 \mathrm{~b}$ & $1018 \mathrm{c}$ & $4 \mathrm{~b}$ & $7 \mathrm{a}$ & $3 \mathrm{a}$ \\
\hline Desiccate & & $1989 \mathrm{a}$ & $2413 \mathrm{a}$ & $2307 \mathrm{a}$ & $1 \mathrm{c}$ & $3 \mathrm{~b}$ & $1 \mathrm{~b}$ \\
\hline Pushing & & $1099 \mathrm{~b}$ & $1227 \mathrm{c}$ & $1368 \mathrm{~b}$ & $6 \mathrm{a}$ & $5 \mathrm{a}$ & $3 \mathrm{a}$ \\
\hline Probability (F test) & & $<0.01$ & $<0.01$ & $<0.01$ & $<0.01$ & $<0.01$ & $<0.01$ \\
\hline
\end{tabular}




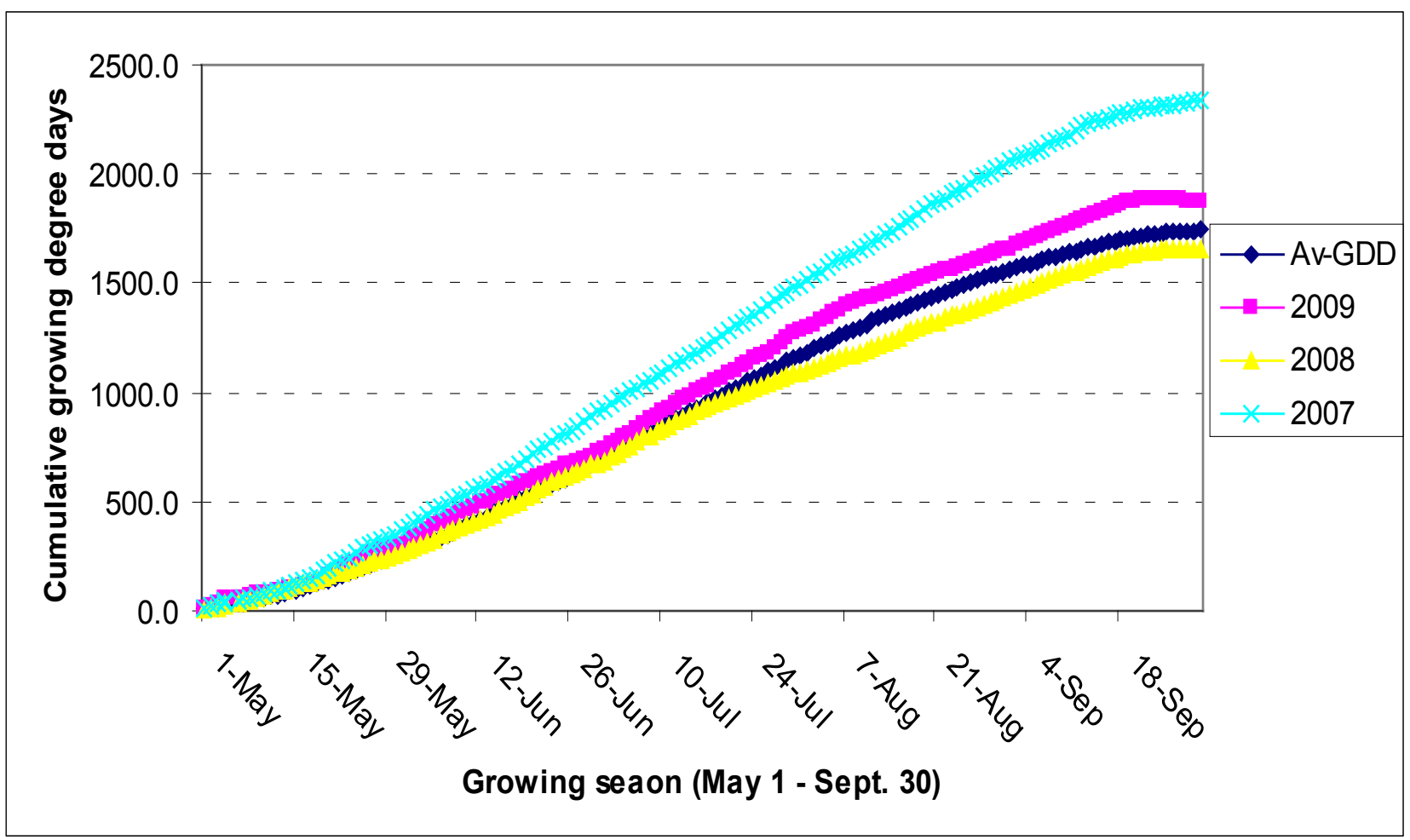

Figure 2. Growing degree days in 2007, 2008 and 2009 collected in test site in Delta Junction area of Alaska.

In all three years, cumulative growing degree days were high in 2007, and low in 2008, with a close to normal year in 2009 compared to the 29 year norm (Fig. 2). In 2007, the growing degree days from May 1 to Sept 30 were 2341. In comparison, the growing degree days for 2008 for the same time period were only 1653 . There were 688 growing degree days shorter in 2008 compared to 2007 (Fig. 2). These differences were also reflected in the green seed content in the direct combining and desiccate treatments. For example, the green seed content for 'Reward' at Delta Junction site was 4 in every 100 seeds in 2007 but 19 in 2008 for direct combining. For desiccate treatment, the green seed content for 'Reward' was only 1 in every 100 seeds in 2007, but 7 in 2008 (Table 2).

Green seed content $\leq 2 \%$ is an industry standard for No. 1 grade commercial canola oil production estimated by Canadian Grain Commission's Grain Research Laboratory (Unger, 2015), which is equivalent to $25 \mathrm{mg} / \mathrm{kg}$ seeds chlorophyll content. By use of glyphosate as a desiccating chemical around Aug. 15 in our study, the growth of canola was prohibited and eventually died. In our experiments, after spraying treatment, there were proximately two weeks prior to harvesting. However, the desiccate treatment in the test areas showed that some polish canola cultivar can reach $\leq 2 \%$ green seed content (such as 'Hysin 110'), while the others can't (such as 'Reward') (Tables 2,3). Our results also showed that in a year with high growing degree days (such as 2007), the desiccating treatment could make $\leq 2 \%$ green seeds for 'Reward'. But in a year with low growing degree days such as 2008, 'Reward' still contained high amount of green seeds even after treating with glyphosate. All those data indicated that glyphosate can desiccate canola, but its effectiveness was dependent on growing degree days and types of cultivars in Alaska. Canola cultivars with a lower growing degree day requirement are still a preference when selecting canola cultivars as a rotational crop in Alaska. 'Hysin 110' had consistently $\leq 2 \%$ green seeds, indicating that it is a viable cultivar for growing in Alaska. The newly released Polish canola cultivar 'AC Sunbeam' also showed a $\leq 2 \%$ green seed content in 2009 . In the consequent years since the end of this study, field experiment with the desiccation treatment with AC 'Sunbeam' have also yielded $\leq 2 \%$ green (data not shown), showing that it was also a good cultivar for Alaska. Given the fact that 'Hysin 110' was purchased by a private company, and has been phased out in the marked for seed production, AC 'Sunbeam' might be the only choice for Alaska farmers in the future. 
Table 4. Viable seed content of harvesting treatments for all tested canola cultivars from 2007 to 2009 for Delta Junction and Fairbanks.

\begin{tabular}{|c|c|c|c|c|c|c|c|}
\hline \multirow[t]{3}{*}{ Variety } & \multirow[t]{3}{*}{ Harvesting tech. } & \multicolumn{3}{|c|}{ Germinated seed (\%) } & \multicolumn{3}{|c|}{ Germinated seed (\%) } \\
\hline & & \multicolumn{3}{|c|}{ Delta Junction } & \multicolumn{3}{|c|}{ Fairbanks } \\
\hline & & 2007 & 2008 & 2009 & 2007 & 2008 & 2009 \\
\hline \multirow[t]{3}{*}{ Reward } & Direct combining & $98 \pm 1$ & $78 \pm 3$ & $94 \pm 2$ & $77 \pm 2$ & $87 \pm 3$ & $91 \pm 2$ \\
\hline & Desiccate & $95 \pm 2$ & $70 \pm 4$ & $95 \pm 1$ & $88 \pm 3$ & $86 \pm 2$ & $96 \pm 1$ \\
\hline & Pushing & $93 \pm 2$ & $91 \pm 1$ & $89 \pm 1$ & $78 \pm 4$ & $80 \pm 3$ & $95 \pm 1$ \\
\hline \multirow[t]{3}{*}{ Hysin 110} & Direct combining & $94 \pm 2$ & $88 \pm 2$ & $94 \pm 2$ & $79 \pm 2$ & $91 \pm 3$ & $82 \pm 2$ \\
\hline & Desiccate & $98 \pm 1$ & $70 \pm 4$ & $93 \pm 1$ & $92 \pm 5$ & $89 \pm 2$ & $93 \pm 1$ \\
\hline & Pushing & $98 \pm 1$ & $91 \pm 1$ & $97 \pm<1$ & $90 \pm 5$ & $94 \pm 1$ & $92 \pm 1$ \\
\hline \multirow[t]{3}{*}{ Maverick } & Direct combining & $86 \pm 2$ & NA & NA & $64 \pm 3$ & NA & NA \\
\hline & Desiccate & $91 \pm 4$ & NA & NA & $89 \pm 4$ & NA & NA \\
\hline & Pushing & $93 \pm 3$ & NA & NA & $75 \pm 4$ & NA & NA \\
\hline \multirow[t]{3}{*}{ Sunbeam } & Direct combining & NA & NA & $92 \pm 1$ & NA & NA & $90 \pm 1$ \\
\hline & Desiccate & NA & NA & $97 \pm 1$ & NA & NA & $91 \pm 2$ \\
\hline & Pushing & NA & NA & $96 \pm 1$ & NA & NA & $83 \pm 1$ \\
\hline \multicolumn{8}{|c|}{ Average for variety } \\
\hline Reward & & $95 \mathrm{a}$ & 78 & $93 \mathrm{~b}$ & $81 \mathrm{~b}$ & $84 \mathrm{~b}$ & $94 \mathrm{a}$ \\
\hline Hysin 110 & & $97 \mathrm{a}$ & 83 & $95 \mathrm{a}$ & $87 \mathrm{a}$ & $91 \mathrm{a}$ & $89 \mathrm{~b}$ \\
\hline Marverick & & $90 \mathrm{~b}$ & NA & NA & $76 \mathrm{~b}$ & & $88 \mathrm{~b}$ \\
\hline Sunbeam & & NA & NA & $95 \mathrm{a}$ & & & \\
\hline $\begin{array}{c}\text { Probability }(\mathrm{F} \\
\text { test) }\end{array}$ & & $<0.01$ & 0.06 & 0.01 & $<0.01$ & 0.01 & $<0.01$ \\
\hline \multicolumn{8}{|c|}{ Average for harvesting methods } \\
\hline $\begin{array}{c}\text { Direct } \\
\text { combining }\end{array}$ & & $92 \mathrm{~b}$ & $83 \mathrm{~b}$ & $93 \mathrm{~b}$ & $73 \mathrm{c}$ & 89 & $88 \mathrm{c}$ \\
\hline Desiccate & & $95 \mathrm{a}$ & $67 \mathrm{c}$ & $95 \mathrm{a}$ & $89 \mathrm{a}$ & 87 & $93 \mathrm{a}$ \\
\hline Pushing & & $95 \mathrm{a}$ & $91 \mathrm{a}$ & $94 \mathrm{ab}$ & $81 \mathrm{~b}$ & 87 & $90 \mathrm{~b}$ \\
\hline $\begin{array}{l}\text { Probability }(\mathrm{F} \\
\text { test) }\end{array}$ & & $<0.01$ & $<0.01$ & 0.01 & $<0.01$ & 0.38 & $<0.01$ \\
\hline
\end{tabular}

With a use of glyphosate in late growing stage, there was a concern on the residual glyphosate in canola seeds. Viability test for seeds from desiccating treatment showed that seeds from the desiccation treatment had germination more than $85 \%$ indicating that seeds were viable and no residual glyphosate might be contained in seeds (Table 4).

With use of new Polish canola varieties in combination with the desiccating pre-harvest technology, canola now has proven to be a good candidate for a rotational crop for interior Alaska. Because of low green seed content, oil from canola seeds grown in interior Alaska can be either used for human consumption or as feedstock for biodiesel. Our experience showed that the direct combine harvesting of immature canola was rather difficult, and additional handling was required after combining.

\section{REFERENCES}

[1] NASS. 2012. Census of Agriculture: Alaska, available at http://www.agcensus.usda.gov/Publications/2012/Full_Repo rt/Volume 1, Chapter_1_State_Level/Alaska/, accessed on April 28, $201 \overline{5}$.

[2] Sharratt, B., M. Zhang, and S. Sparrow. 2006a. Twenty years of tillage research in subarctic Alaska: I. Impact on soil strength, aggregation, roughness and residue cover. Soil \& Tillage Research 91:75-81.

[3] Sharratt, B., M. Zhang, and S. Sparrow. 2006b. Twenty years of tillage research in subarctic Alaska: II. Impact on soil hydraulic properties. Soil \& Tillage Research 91:82-88. 
[4] Unger, E.H. 2015. Processing. In "Canola: Chemistry, Production, Processing and Utilization" pp. 163-188, J.K Duan, N.A. M. Eskin, and D. Hicking (eds). Academic Press and AOCS Press.
[5] Zhang, M., S. Sparrow, C. Lewis, and C. Knight. 2007. Soil Properties and barley yield under 20-year experiment of tillage, straw management, and nitrogen application rate in the subarctic area of Alaska. Agriculture ScandinaviaSection B Soil \& Plant Science. 57:375-383. 